\title{
Design and Fabrication of Acoustic Wave Actuated Microgenerator for Portable Electronic Devices
}

\author{
${ }^{1}$ Tenghsien Lai, ${ }^{2}$ Changhan Huang, and ${ }^{2}$ Chingfu Tsou \\ ${ }^{1}$ The Graduate Institute of Electrical and Communications Engineering, Ph.D. Program, \\ Feng Chia University, 100 Wenhwa Road, Seatwen, Taichung, Taiwan, 40724 R.O.C. \\ ${ }^{2}$ Department of Automatic Control Engineering, Feng Chia University, \\ 100 Wenhwa Road, Seatwen, Taichung, Taiwan, 40724 R.O.C.,
}

\begin{abstract}
An acoustic wave actuated microgenerator for power system applications in mobile phone was design, fabricated, and characterized. We used the acoustic wave of human voices or speakerphone by way of an electromagnetic transducer to produce electrical power for charging or to run a portable electronic device. The proposed microgenerator is composed of a planar coil, a suspension plate with supporting beams and a permanent magnet. In this paper, the dynamic response of the suspension structure and the variation of the induced magnetic flux were characterized by using commercial finite element analysis and Ansoft Maxwell EM3D software, respectively. The electroplating nickel and silicon bulk micromachining techniques were used to fabricate the suspension plate and planar coil, and by integrating a permanent magnet as well as wafer to wafer adhesion bonding to accomplish the microgenerator assembly. The experimental results shown the typical microgenerator with a planar dimension of $3 \mathrm{~mm} \times 3 \mathrm{~mm}$, the maximum induce-voltage 0.24 $\mathrm{mV}$ was generated at the driving frequency of $470 \mathrm{~Hz}$. The dynamic response of microgenerator can be designed to meet a specific acoustic driving frequency to increase the efficiency of energy harvesting.
\end{abstract}

\section{INTRODUCTION}

The past few years have seen an increasing focus on energy harvesting issue, including power supply for portable electric devices. Utilize scavenging ambient energy from the environment could eliminate the need for batteries and increase portable device lifetimes indefinitely. Several different ambient sources, including solar, vibration and temperature effect, have already exploited [1-3]. In particular, scientists are currently trying to find more efficient ways of utilizing solar cells for electricity production [4-6]. Each energy source should be used in suitable environment, therefore to produce maximum efficiency.

Ambient energy generators have the potential to replace battery power as an energy source in a variety of practical applications. For example, kinetic (or vibration) energy generators harvest electrical energy from movement present in the application environment. Various kinetic generators use piezoelectric materials [7 10], electrostatic [11 13] and electromagnetic [14 20] transduction mechanisms. Piezoelectric materials are perfect candidates for vibrational energy scavenging as they can efficiently convert mechanical strain to an electrical charge without any additional power, but it is difficult to implement at micro-scale. Electrostatic is a good solutions for the construction of microgenerators because of its relative ease of integration with microelectronics. The disadvantage of this approach is that a separate voltage source is required to charge the capacitor. Electromagnetic conversion uses vibration to move a conductor in a magnetic field. Existing prototypes generate low voltage output to be usable. However, the amount of energy generated by those approaches depend the application environment and the efficiencies of the generators and the power conversion electronics. The goal is to develop miniature, self-contained and renewable power supplies that convert energy from an existing source in the environment into electrical energy.

In this study, we present an acoustic wave actuated microgenerator with high output voltage suitable for commercial portable electronic devices. We use the energy of acoustic waves, such as the sound from human voices or speakerphone, to actuate a MEMS-type electromagnetic transducer. This provides a longer device lifetime and greater power system convenience. It is convenient to integrate MEMS-based microgenerators with small or portable devices. Our aim is to run a small electronic device, like a cell phone, and may soon be able to power a laptop.

\section{Design And Analysis}

The proposed acoustic wave actuated microgenerator, as shown the Fig. 1, consists of a top wafer with planar coil and a bottom wafer with a suspended flat and support beams as well as a high magnetic energy permanent magnet. The top wafer is etched through its thickness by anisotropic wet etching $(\mathrm{KOH})$. The wafer-to-wafer bonding process is aligned to ensure correct placement of the coil relative to the magnet. The top surface of the magnet is in line with the planar coil. The thickness of the magnet is same as that of the top wafer. Thus, the planar coil has tight gap spacing with the permanent magnet; this enhances the induced voltage. Larger output power can be obtained by link an array of identical microgenerators. 


\section{DTIP}

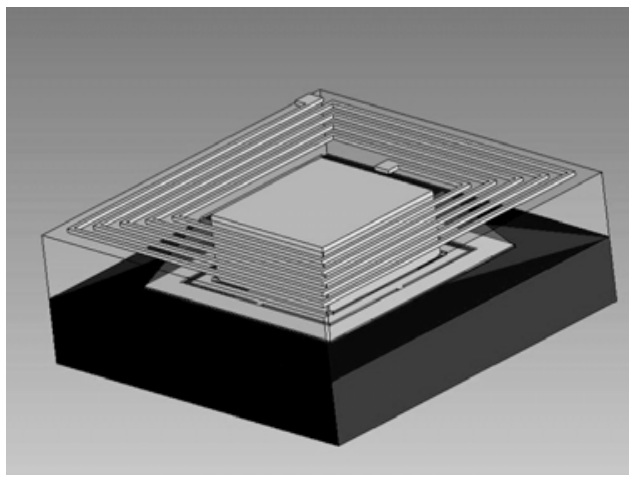

(a)

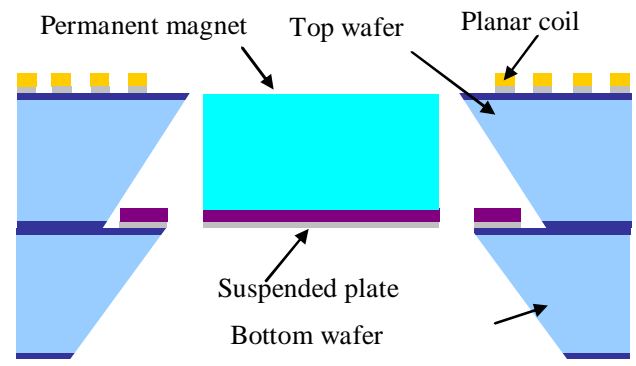

(b)

Figure 1. Design concept of the microgenerator: (a) 3-D and (b) Cross-section view.

The commercial software ANSYS was used to simulate the resonant frequency and vibration mode of suspension microstructure for the actuation frequencies produced by human vocal cords. The purpose is to achieve the micro-generator with higher charge collection efficiency in a small area under a specific driving frequency. Noting the frequency range of 200 $\mathrm{Hz}-1.5 \mathrm{kHz}$ in sound pressure level characteristics is the most important range in human vocal and electrical acoustic instruments, as shown in Fig. 2. The schematic diagram of the mechanical structure is shown in Fig. 3(a). The middle point of each suspension beam is fixed to the silicon substrate. The material parameters and device dimensions of the microgenerator are shown in table 1. The typical simulated result for the suspended flat with a permanent magnet is shown in Fig. 3(b). The figure demonstrates the first resonance mode of the microstructure is an out-of-plane piston-like motion and the natural frequency is $1012 \mathrm{~Hz}$.

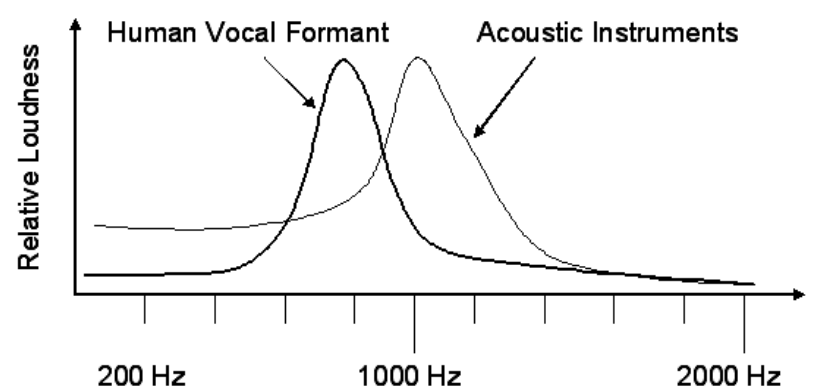

Figure 2. Frequency responses of human vocal formant and commercial acoustic instruments
Table 1 Material and geometry parameters of microgenerator for analysis process

\begin{tabular}{|c|c|c|}
\hline Material parameters & Value & Scale \\
\hline Young's modulus $(\mathrm{E})$ & $2 \times 10^{11}$ & $\mathrm{~Pa}$ \\
\hline Structure density $\left(\sigma_{1}\right)$ & 8910 & $\mathrm{~kg} / \mathrm{m}^{3}$ \\
\hline Magnet density $\left(\sigma_{2}\right)$ & 9000 & $\mathrm{~kg} / \mathrm{m}^{3}$ \\
\hline Geometry parameters & Value & Scale \\
\hline Beam length $(\mathrm{L})$ & 800 & $\mu \mathrm{m}$ \\
\hline Beam width $(\mathrm{W})$ & 60 & $\mu \mathrm{m}$ \\
\hline Beam thickness $(\mathrm{H})$ & 20 & $\mu \mathrm{m}$ \\
\hline Flat length $\left(\mathrm{X}_{1}\right)$ & 2000 & $\mu \mathrm{m}$ \\
\hline Flat width $\left(\mathrm{Y}_{1}\right)$ & 2000 & $\mu \mathrm{m}$ \\
\hline Flat thickness $\left(\mathrm{Z}_{1}\right)$ & 20 & $\mu \mathrm{m}$ \\
\hline Magnet length $\left(\mathrm{X}_{2}\right)$ & 2000 & $\mu \mathrm{m}$ \\
\hline Magnet width $\left(\mathrm{Y}_{2}\right)$ & 2000 & $\mu \mathrm{m}$ \\
\hline Magnet thickness $\left(\mathrm{Z}_{2}\right)$ & 500 & $\mu \mathrm{m}$ \\
\hline
\end{tabular}

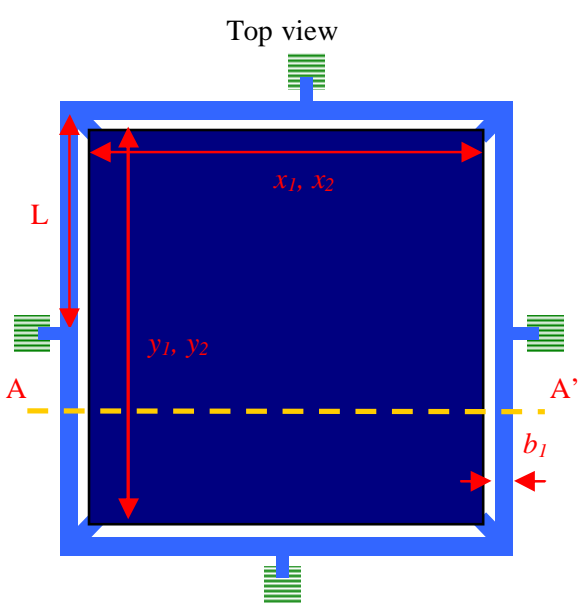

AA' cross-section view

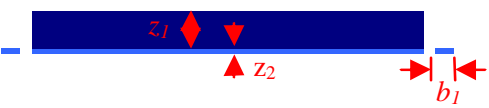

(a)

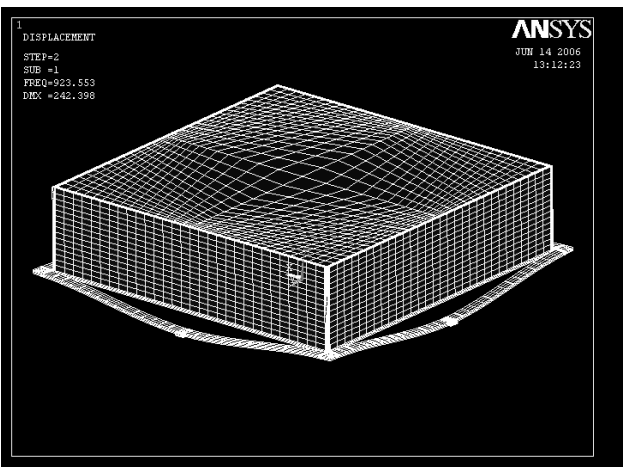

(b)

Figure 3. (a) The design of the mechanical structure and (b) its first modal (piston-like motion) of vibration that simulated by ANSYS 


\section{DTIP}

The electromagnetic software Ansoft Maxwell EM3D was employed to characterize the variation magnetic flux due to the mechanical and electrical energy conversion is coupled through the magnetic field across the conductor coil. In this simulation process, we design fifteen-turn square spiral coil made from $\mathrm{Cu}$ with $20 \mu \mathrm{m}$ gap spacing on a substrate. Each coil has a width of $20 \mu \mathrm{m}$ and a thickness of $10 \mu \mathrm{m}$. The first-turn coil has one winding over the edges of the magnet. The size of magnet is same as in table 1 . Figure 4 show the typical simulation result for the magnet above one-turn planar coil at a distance of $10 \mu \mathrm{m}$. The figure shows that the bottom edge of magnet closer to the coil, the more magnetic flux is induced. The magnetic flux drops very rapidly as the magnet moves away from the center of the coil. By the post process function of the Maxwell EM3D, the magnetic flux of each planar coil was calculated. For a $3 \mathrm{~mm} \times 3$ $\mathrm{mm}$ microgenerator, the estimated output voltage is approximately $0.58 \mathrm{mV}$ at $1 \mathrm{KHz}$ driving frequency with \pm 50 $\mu \mathrm{m}$ amplitude range.

\section{FABRICATION}

To meet the requirements of high-voltage output under a specific range of driving frequency, we used electroplating and bulk micromachining to fabricate the planar coil and suspension microstructure, and then integrating an $\mathrm{Nd}-\mathrm{Fe}-\mathrm{B}$ based permanent magnet on the suspended plate. The fabrication processes of the planar coil and suspension microstructure are shown in Fig. 5 and Fig. 6, respectively. Figure 5 shows the fabrication processes of the planar coil that starts with a $500 \mu \mathrm{m}$ thick 4-inch $\langle 100\rangle$ silicon wafer (Fig. 5a). First, the (100) single crystal silicon substrate was placed in a furnace at $1050{ }^{\circ} \mathrm{C}$ for 150 minutes to grow a $1 \mu \mathrm{m}$ thick wet thermal oxide layer (Fig. 5b). Then a $0.1 \mu \mathrm{m}$-thick $\mathrm{Cr}$ film and a $0.2 \mu \mathrm{m}$-thick Ni film were deposited by thermal evaporation as adhesion and seed layers respectively (Fig. 5c). Next, a $25 \mu$ m-thick of photoresist AZ4620 was spun and patterned by photolithography. After that, a Ni layer was deposited by electroplating to fabricate the planar coil, and then the residue photoresist was removed (Fig. $5 \mathrm{~d})$. It is noted that the $\mathrm{Cu}$ with the excellent conductivity is suitable as the coil material than the $\mathrm{Ni}$, however the process of electroplating $\mathrm{Ni}$ is easy to verify the possibility of our design and to improve the yield. To isolate the electrical properties, the exposed region of $\mathrm{Cr}$ adhesion and $\mathrm{Ni}$ seed layers were etched by a wet etch solution (Fig. 5e). The backside oxide layer was patterned by photolithography and then etched by BOE solution (Fig. 5f). After that, the exposed regions of silicon were wet etched by $\mathrm{KOH}$ solution $(25 \%)$ at $80^{\circ} \mathrm{C}$ for 4 hour to through the wafer thickness, and finally $\mathrm{SiO} 2$ layers were etched by $\mathrm{HF}$ to obtain a single layer of Ni microstructure (Fig. $5 \mathrm{~g}$ ).

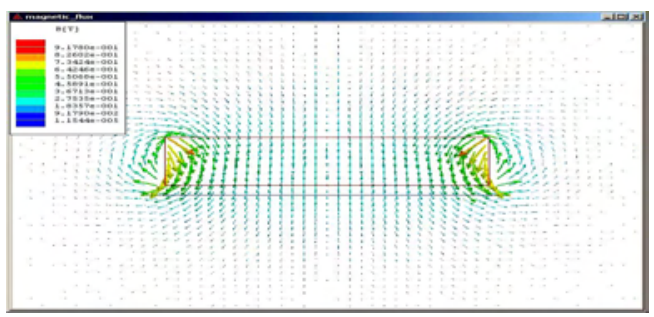

(a)

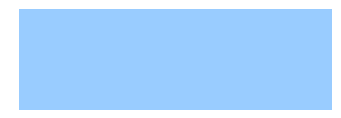

(b)

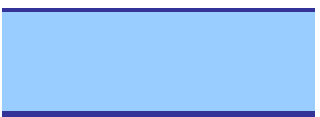

(c)

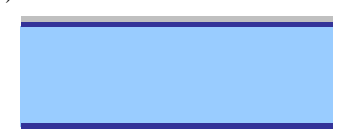

(d)

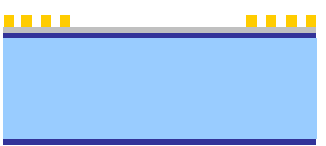

Figure 5. Fabrication process of planar coil

(a)

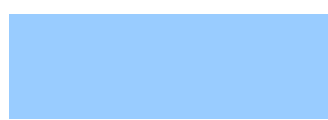

(b)

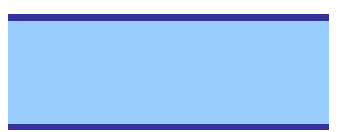

(c)

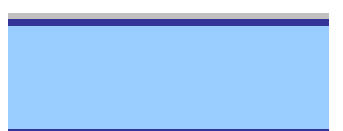

(e)
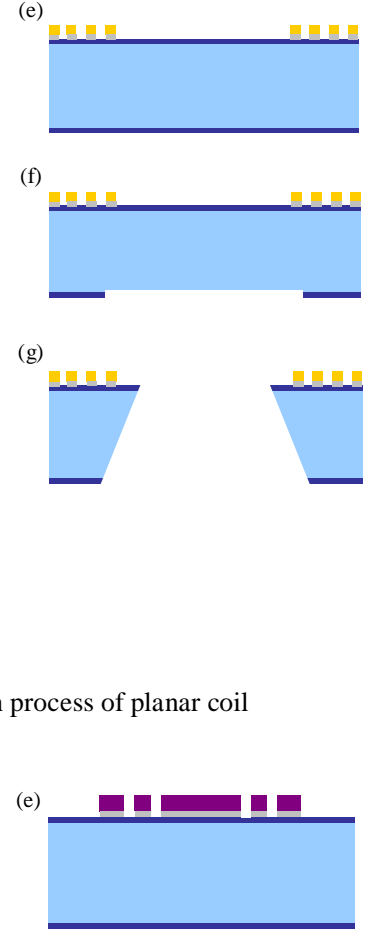

(f)
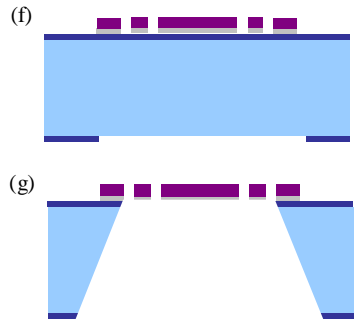

(d)

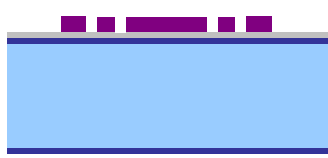

Figure 6. Fabrication process of suspension microstructure

The fabrication process of the suspension microstructure in Fig. 6(a) (g) is same as that of the planar coil except step (d) and the mask layout. The $\mathrm{Ni}$ suspension microstructure is deposited by electroplating technology and is $20 \mu \mathrm{m}$ thick. The electroplated $\mathrm{Ni}$ film has the advantages of low-residual stress, high density, and superior mechanical strength and can be formed as a high-aspect-ratio microstructure by photolithography [21-23]. As to the mechanical properties of electroplated Ni film from the previously works [24-27] referred and the quasi-static bending beam test using nanoindentation system in our research [28] presented are summarized in Table 2 .

Figure 4. The magnetic flux in the space simulated by Ansoft MaxwellEM3D 


\section{DTIP}

Table 2 Mechanical properties of electroplated Ni film.

\begin{tabular}{|c|c|c|}
\hline References & $\begin{array}{c}\text { Young's modulus } \\
\mathrm{E}(\mathrm{GPa})\end{array}$ & $\begin{array}{c}\text { Yield strength } \\
\sigma \mathrm{y}(\mathrm{MPa})\end{array}$ \\
\hline$[11-14]$ & $125 \sim 231$ & $323 \sim 1550$ \\
\hline $\begin{array}{c}\text { Our research presented } \\
{[15]}\end{array}$ & $179 \sim 225$ & $660 \sim 1120$ \\
\hline
\end{tabular}

\section{EXPERIMENTAL Results}

This research has successfully designed and fabricated an acoustic wave actuated microgenerator using the presented processes. Typical fabrication results for the planar coil and suspended plate are shown in Fig. 7 and Fig. 8, respectively. Figure 7 show the square spiral coil has fifteen-turn with $20 \mu \mathrm{m}$ gap and each planar coil has a width of $20 \mu \mathrm{m}$ and a thickness of $10 \mu \mathrm{m}$. The measured resistance from pads is approximate $58 \Omega$. The size of etching through-hole is $2 \mathrm{~mm} \times 2 \mathrm{~mm}$. Figure 8 shows the suspension microstructure with slight bending deformation from the fix end is due to the effect of residual stresses. This result would not affect the latter assembly and performance measurement of microgenerator significantly. Fig. 9 shows the top view of a $2 \mathrm{~mm} \times 2 \mathrm{~mm} \times 0.5 \mathrm{~mm}$ microgenerator with a permanent magnet. The pad setting is for the wire bond to output the induced electrical energy. The residual magnetic flux density $(\mathrm{Br})$ of the magnet is 1.2 Tesla, according to the manufacturer's data.

To understand the dynamic characteristic and the performance of the microgenerator, Laser Doppler Vibrometer (LDV) and an acoustic speaker with a power of $3 \mathrm{~W}$ were employed to measure the resonance frequency and induced-voltage of the microgenerator, as shown in Fig. 10. The functions of the power supply and oscilloscope are to provide the initial bias-voltage to detect the output voltage, respectively. The gap spacing between speaker and microgenerator was 5 $\mathrm{mm}$. After a driving voltage of $1 \mathrm{~V}$ (peak to peak) with sin wave signal has been input the speaker, the dynamic responses measured at atmospheric pressure by LDV is show in Fig. 11(a) and 11(b). Fig. 11(a) shown the magnet had a maximum displacement $2.8 \mu \mathrm{m}$ at the first resonance frequency (piston-like motion) of $470 \mathrm{~Hz}$.

Also, if the driving voltage is increased to $10 \mathrm{~V}$, a maximum out-of-plane displacement of $11.5 \mu \mathrm{m}$ can be achieved, as shown in Fig. 11(b). In this case, the measured induce-voltage at the first resonance frequency $470 \mathrm{~Hz}$ is $0.24 \mathrm{mV}$ (peak to peak) when the driving voltage is $1 \mathrm{~V}$. Therefore, using the proposed fabrication methodology and operation principle, we are able to manufacture a microgenerator with high-power output. The generated energy can apply to an electric cell or as a secondly battery, although the measured amount of electrical energy could not supply enough power to run a cell phone. In addition, high induced-voltage can be achieved by using the coil with high conductivity such as $\mathrm{Cu}$ or under a specific driving frequency by increasing the thickness and the number of coils, as well as by reducing the gap spacing between coil and permanent magnet.

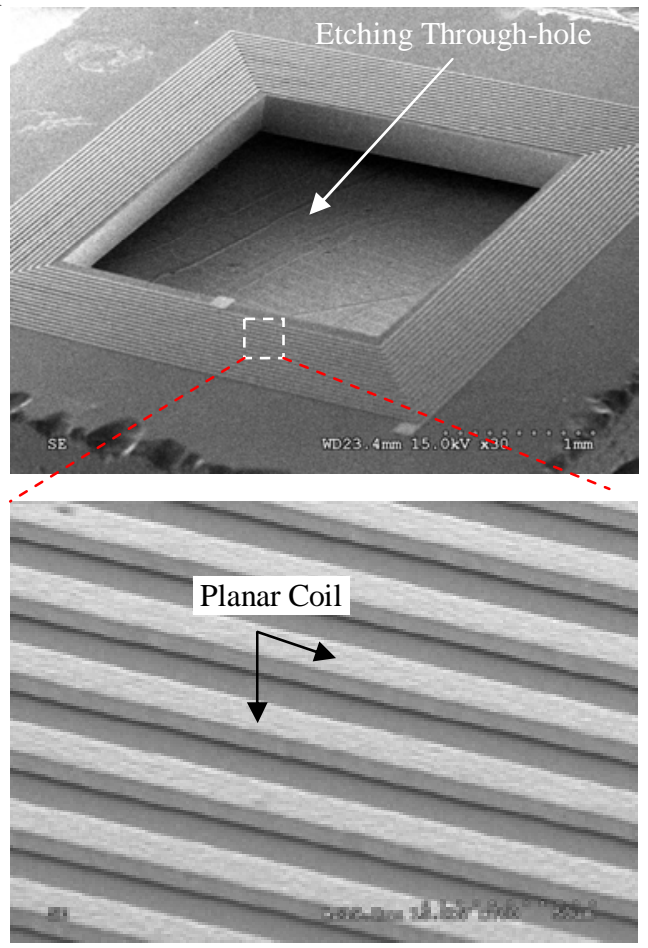

Figure 7. SEM image of the top wafer with planar coil

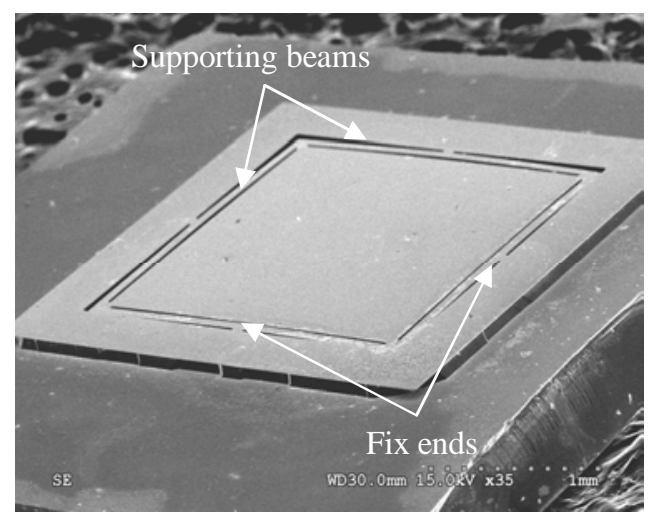

Figure 8. SEM image of the bottom wafer with suspended microstructure

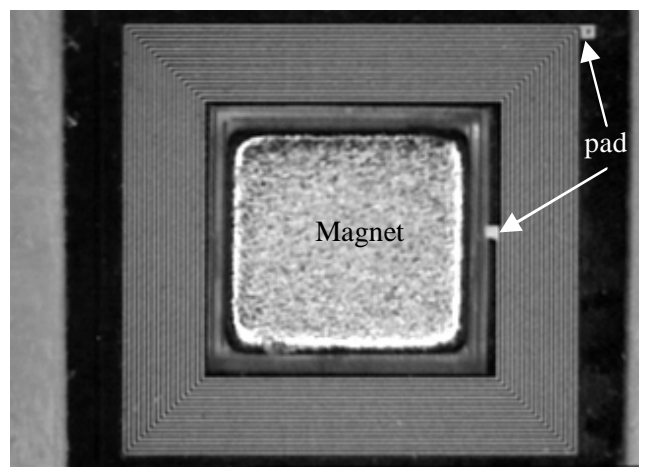

Figure 9. Top view of optical microscopy image of the assembled microgenerator 


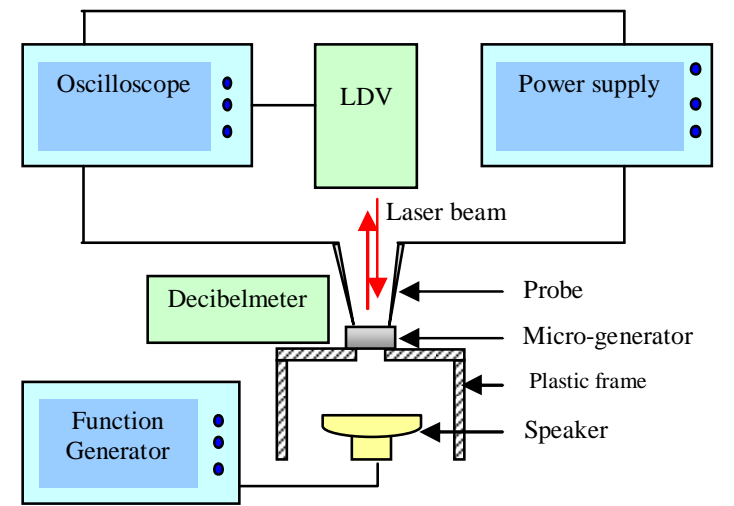

Figure 10. Experiment set up for the measurement of dynamic characteristic of microgenerator

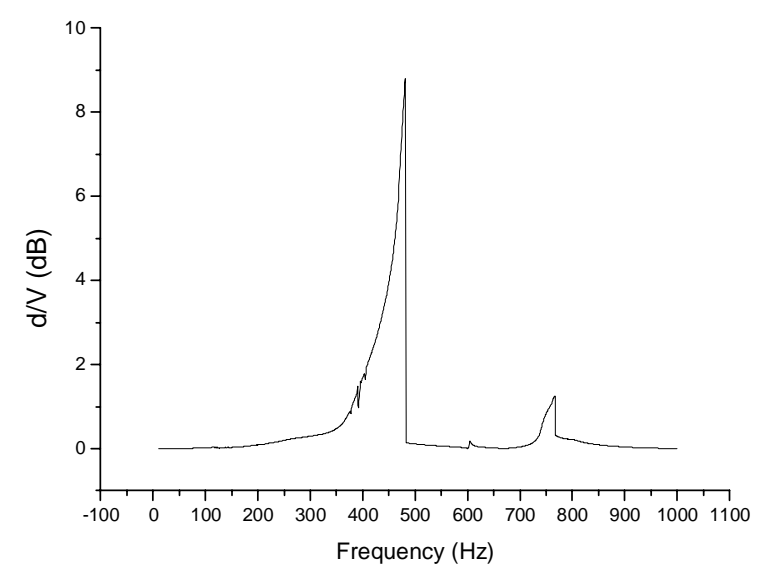

(a)

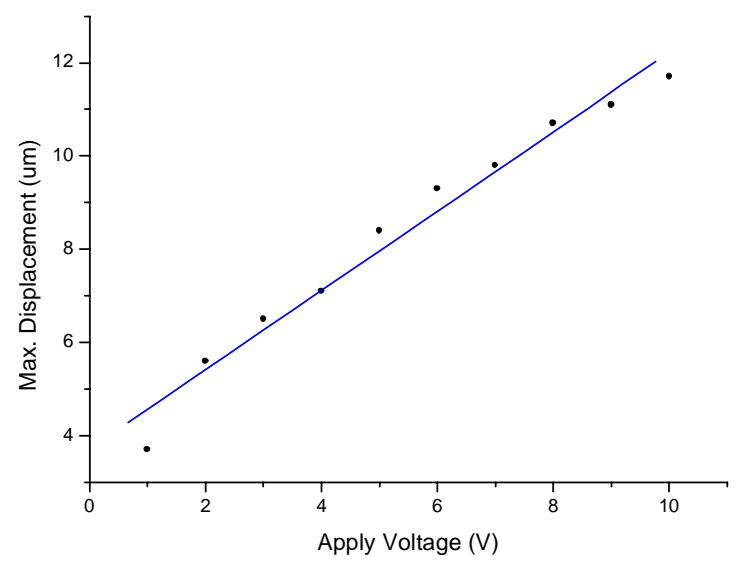

(b)

Figure 11. Measurement results of microgenerator: (a) the dynamic response illustration at the apply voltage of $1 \mathrm{~V}$ and (b) the out-of-plane displacement vs. applied voltage at the resonant frequency of $470 \mathrm{~Hz}$.

Comparing experimental results to analytic predictions, we note many differences in first natural frequency and induced-voltage. We suggest many differences arise from the error in material parameters and in manufacturing geometry precision, the effect of the thickness of suspension structure may have been particular disruptive. The measured thickness of electroplated $\mathrm{Ni}$ is about $14 \mu \mathrm{m}$, which is less than the $20 \mu \mathrm{m}$ in the proposed design. In addition, the measured amplitude is only $\pm 3 \mu \mathrm{m}$, also less than the intended $\pm 50 \mu \mathrm{m}$ significantly. However, we can predict the performance of the microgenerator accurately by using available data from past experiments and eliminating all errors associated with critical device dimensions to meet some specific acoustic driving frequency.

\section{Conclusion}

A novel configuration for an electromagnetic microgenerator has been modeled and confirmed by experiments at a small macroscopic scale. The performance of the planar coil and suspension structure has been characterized by software analysis and experimental results. Fabrication result show a $3 \mathrm{~mm} \times 3$ $\mathrm{mm} \times 1 \mathrm{~mm}$ microgenerator had maximum induce-voltage 0.24 $\mathrm{mV}$ obtained at a driving frequency of $470 \mathrm{~Hz}$. Based on a MEMS type electromagnetic transducer, our design provides several important features such as the planar coil has the same level and a small gap spacing with the permanent magnet in in-plane to enhance the induced voltage. The suspension microstructure can be modified appropriately to meet a specific acoustic driving frequency to increase the efficiency of energy conservation. The small size, high efficiency, and potentially low cost make microgenerator desirable for numerous portable electronic devices. In the future, microgenerators can be combined with batteries and integrated circuit to make energy harvesting system for small devices.

\section{ACKNOWLEDGMENT}

This project was supported by the National Science Council of Taiwan under grant of NSC-95-2221-E-035-016. The authors appreciate the Precision Instrument Support Center of Feng Chia University, and the NSC National Nano Device Laboratory (NDL) in providing the fabrication facilities.

\section{REFERENCES}

R.P. Raffaelle, J. Underwood, D.Scheiman, J. Cowen, P. Jenkins, A.F. Hepp, J. Harris and D.M. Wilt, "integrated solar power system," 28th IEEE Photovoltaic Specialists Coference, Pages 1370-1373, 2000

S. Roundy, P.K. Wright and K.S. Pister, "Micro-electrostatic vibration to electricity converters," Proceedings of the ASME International Mechanical Engineering Congress and Expo, 2002

M. Strasser, R. Aigner, C. Lauterbach, T. F. Sturm, M. Franosch, and G. Wachutka, "Micromachined CMOS Thermoelectric Generators as On-Chip Power Supply," Proc. Transducers '03, pp, 45-49, 2003.

H. E. A. Elgamel, "High efficiency polycrystalline silicon solar cells using low temperature PECVD process", IEEE Transactions on Electron Devices, Vol. 45, pp. 2131 2137, 1998.

S. K. Rotich, J. G. Smith, A. G. Evans, and A. Brunnschweiler, "Micromachined thin solar cells with a novel light trapping scheme", J. Micromech. Microeng., Vol. 8, pp. 134-137, 1998.

G. F. X. Strobl, T. Bergunde, W. Kostler, R. Kern, M. Meusel, G. LaRoche, W. Zimmermann, A. W. Bett, F. Dimroth, W. Geens, S. Taylor, E. Fernandez, L. Gerlach, C. Signorini, and G. Hey, "European roadmap of multijunction solar cells and qualification ststus", 2006 IEEE 4th world conference on Photovoltaic Energy Conversion, Vol. 2, Waikoloa, Hawaii, May, pp. 1513-1516, 2006.

[7] P. Glynne-Jones, S.P. Beeby, N.M. White, "Towards a piezoelectric vibration-powered microgenerator," Science, Measurement and Technology, IEE Proceedings-Volume 148, Issue 2, Pages 68 - 72, March 2001

[8] S. Roundy, P.K. Wright and J. Rabaey, "A steady of low level vibrations as a power source for wireless sensor nodes," Computer 


\section{DTIP}

Communications, vol.26, Pages 1131-1144, 2003

[9] S. Roundy and P.K. Wright, "A piezoelectric vibration based generator for wireless electronics," Smart materials and Structure, vol.13, pages1131-1142, 2004

[10] H.A. Sodano, D.J. Inman and G..Park, "A review of power harvesting from vibration using piezoelectric materials," The Shock and Vibration Digest, vol.36, Pages 197-205, 2004

[11] B.H. Stark, T.C. Green, "Comparison of SOI power device structures in power converters for high-voltage low-charge electrostatic microgenerators, ", IEEE Transactions on Electron Devices, Volume 52, Issue 7, Pages:1640-1648, July 2005

[12] S. Meninger, J.O. Mur-Miranda, R.Amirtharajah, A.P. Chandrakasan and J.H. Lang, "Vibration-to-electric energy conversion," IEEE Transactions on Very Large Scale Integration (VLSI) System, Vol.9, Pages64-76, 2001

[13] S. Roundy, P.K. Wright and K.S. Pister, "Micro-electrostatic vibration to electricity converters," Proceedings of the ASME International Mechanical Engineering Congress and Expo, 2002

[14] R.Amirtharajah and A.P. Chandrakasan, "Self-Power signal Processing using vibration-based power generation," IEEE journal of Solide -State Circuits, Vol.33, Pages 687-695,1998

[15] M. Mizuno and D.G. Chetwynd, "Investigation of a resonance microgenerator," Journal of Micromechanics and Microengineering, Volume 13, Pages 209-216, Number 2 2003,

[16] H. Kulah and K. Najafi, "An electromagnetic micro power generator for low frequency environmental vibrations," 17th IEEE International Conference on Micro Eletro Mechanical System (MEMS), Pages 237-240, 2004

[17] C.B. Williams and R.B. Yates, "Analysis of a micro-electric generator for Microsystems," Sensors and Actuators A: Physical, Volume 52, Issues 1-3, Pages 8-11, March-April 1996

[18] C. Sherawood and R.B. Yates, "Development of an electromagnetic microgenerator," Electronics Letters 23rd, Vol. 33, No.22, October 1997

[19] W.J. Li, Terry C.H. Ho, Gordon M.H. Chan, Philip H.W. Leong and H.Y. Wong, "Infrared signal transmission by a laser-micromachined vibration-induced power generator," 2000 Proceedings of the 43rd IEEE Midwest Symposium on Circuits and Systems, Volume 1, Page(s):236 - 239, 8-11 Aug 2000

[20] S.P. Beeby, M.J. Tudor, E. Koukharenko, N.M. White, T. O’Donnell C. Saha, S. Kulkarni and S. Roy, "Design and performance of a microelectromagnetic vibration-powered generator," 2005. TRANSDUCERS'05. The 13th International Conference on Solid-State Sensors, Actuators and Microsystems, Volume 1, Page(s):780 - 783, June 5-9, 2005.

[21] W. N. Sharpe, D. A. La Van, and R. L. Edwards, "Mechanical properties of LIGA-deposited nickel for MEMS transducers," Proc. Int. Conf. Solid-State Sensors and Actuators, Chicago, IL, June.1997, pp. 607-610.

[22] E. Mazza, S. Abel, and J. Dual, "Experimental determination of mechanical properties of $\mathrm{Ni}$ and Ni-Femicrobars," Microsystem Technologies, Vol. 2, 1996, pp. 197-202.

[23] S. Greekand and F. Ericson, "Young's Modulus, yield strength and fracture strength of microelements determined by tensile testing", Proc. MRS Symposium Proceedings, Vol. 518, 1998, pp.51-56.

[24] W. N. Sharpe, D. A. La Van, and R. L. Edwards, "Mechanical properties of LIGA-deposited nickel for MEMS transducers," Proc. Int. Conf. Solid-State Sensors and Actuators, Chicago, IL, June.1997, pp. 607-610.

[25] E. Mazza, S. Abel, and J. Dual, "Experimental determination of mechanical properties of $\mathrm{Ni}$ and Ni-Femicrobars," Microsystem Technologies, Vol. 2, 1996, pp. 197-202.

[26] S. Greekand and F. Ericson, "Young's Modulus, yield strength and fracture strength of microelements determined by tensile testing", Proc. MRS Symposium Proceedings, Vol. 518, 1998, pp.51-56.

[27] L. S. Stephens, K. W. Kelly, S. Simhadri, A. B. McCandless, and E. I. Meletis, "Mechanical property evaluation and failure analysis of cantilevered LIGA nickel microposts," Journal of MEMS, Vol. 10, 2001, pp. 347-359.

[28] C. Tsou, C. Hsu, W. Fang, T. S. Lai and H. C. Li, "Bending Characterization of Electroplated Nickel Microbeams," Sensors and Materials, Vol. 19, No. 2, pp. 79-94, 2007. 